\title{
Modern Health Service Utilization and Associated Factors among Adults in Southern Ethiopia
}

\author{
Shimelash Bitew Workie ${ }^{(D)},{ }^{1}$ Niguse Mekonen, ${ }^{1}$ Mulugeta W. Michael, ${ }^{1}$ Getahun Molla, ${ }^{2}$ \\ Solomon Abrha, ${ }^{1}$ Zewde Zema $^{3}$ and Takele Tadesse ${ }^{1}$ \\ ${ }^{1}$ School of Public Health, College of Medicine and Health Sciences, Wolaita Sodo University, Wolaita Sodo, Ethiopia \\ ${ }^{2}$ School of Medicine, College of Medicine and Health Sciences, Wolaita Sodo University, Wolaita Sodo, Ethiopia \\ ${ }^{3}$ School of Pharmacy, College of Medicine and Health Sciences, Wolaita Sodo University, Wolaita Sodo, Ethiopia \\ Correspondence should be addressed to Shimelash Bitew Workie; sbitew0@gmail.com
}

Received 24 July 2020; Revised 25 November 2020; Accepted 31 December 2020; Published 11 January 2021

Academic Editor: Animesh Jain

Copyright (c) 2021 Shimelash Bitew Workie et al. This is an open access article distributed under the Creative Commons Attribution License, which permits unrestricted use, distribution, and reproduction in any medium, provided the original work is properly cited.

\begin{abstract}
Background. The Ethiopian government is striving to improve the health status of its population through the expansion and strengthening of primary health care services in both rural and urban settings of the country. The study aimed to measure modern health service utilization and associated factors in Wolaita Sodo town, Ethiopia. Method. A cross-sectional study design was implemented from May to June 2019 in Wolaita Sodo town, Ethiopia. All 786 study participants were selected by multistage systematic random sampling. Data were collected by face-to-face interviews using a pretested structured questionnaire. Data were collected by an open data kit. Stata window version 15.0 was also employed for statistical analysis. Multiple logistic regression was conducted, and a 95\% confidence interval was considered for interpretation. Result. Health service utilization was $77.2 \%$ with ( $95 \%$ CI of $74.1 \%, 80.0 \%)$. In terms of health facilities in which they visit, first $50.6 \%$ were at the public health center and $25.5 \%$ of them were at Teaching and Referral Hospital. Respondents with marital status married and widowed have higher odds of utilizing health services compared to single marital status (AOR: 2.96; 95\% CI: 1.7-5.2 and 9.0; 95\% CI: 1.69-48.0), respectively. Respondents with middle and highest wealth status have higher odds of health service utilization than poor wealth status with AOR (1.75 95\% CI 1.03-2.97 and 1.58 95\% CI; 1.01, 2.77). Similarly, respondents who had chronic disease and perceived poor health status have higher odds of health service utilization. Conclusion. Modern health services utilization was found to be unsatisfactory. Being married, wealth status being middle and high, having chronic health conditions, and having poor perceived health status were found to have a statistically significant association with health service utilization.
\end{abstract}

\section{Introduction}

The 2030 Sustainable Development Goals (SDG) emphasize having all people receive the quality health services they need without financial hardship. Critical to attaining universal health coverage (UHC) is a formal monitoring mechanism to assess progress. The UHC service coverage index, measuring progress on SDG indicator 3.8.1, increased from a global average of $45 \%$ in 2000 to $66 \%$ in 2017 [1].

The health service utilization rate in Africa is low and sub-Saharan Africa, in particular, is very low, ranging from only 0.2 annual visits to 2 visits [2].
The utilization of health care services is an important public health and policy issue in developing countries for the achievement of universal health coverage [3]. Access to and utilization of health services are key to the improvement of health outcomes in low- and middle-income countries (LMICs) [4]. In recent years, the Ethiopian government is investing lots of money to improve the health care of its nation. This is considered one of the top lists of transformational agendas by the government [5]. According to the Ministry of Health, due emphasis is given to the improvement of health care services towards the expansion and strengthening of primary health care emphasizing maternal and child health and 
prevention of both communicable and noncommunicable diseases. Hence the government believes that the delivery of quality health services at all levels of the stages of the health system is central to improving the health status of the population. Improving the quality of health services implies the improvement of supply and demand-side interventions and the health and health-related regulatory aspect [6].

Ethiopia is one of the sub-Saharan countries most affected by the high disease burden reflected by the high rates of maternal and child mortality. Based on 2015 point estimates, noncommunicable diseases were the leading contributor to age-standardized death rates in Ethiopia, causing 710.9 (468.8-1036.2) deaths per 100,000; however, communicable, maternal, neonatal, and nutritional (CMNN) diseases were the leading causes of premature mortality, with a rate of $17,950.6(14,377.9-22,768.8)$ per 100,000 . CMNN diseases caused more deaths in young people, those between 15 and 49, than other causes in 2015 [7].

Health service utilization is one of the key elements for alleviating morbidity and mortality. In Ethiopia, different studies tried to estimate health service utilization. Therefore, the present study aims to measure the utilization of health service of adults and associated factors in Wolaita Sodo town, Ethiopia, and to suggest ways to improve and strengthen health centers to improve quality of care and reduce the burden on university hospitals.

\section{Methods}

2.1. Study Area. The study was conducted in Wolaita Sodo town which is the capital city of Wolaita Zone. The town is southwest $327 \mathrm{~km}$ far from Addis Ababa and $166 \mathrm{~km}$ South from the regional Capital city, Hawassa. The town is located at an altitude of 1500-2500 $\mathrm{m}$ above sea level with an area of $82.1 \mathrm{~km}^{2}$. The town has three subtowns and 11 administrative Kebele. The estimated total population number is 143,438 with 70285 males, 73153 females. The town has $14,551 \mathrm{HH}$, one referral hospital, one private hospital, 11 health posts, 3 health centers, and 24 private health institutions.

2.2. Study Design and Period. Community-based crosssectional study design was implemented from May to June 2019.

2.2.1. Source Population. All adults in Wolaita Sodo town were the source population. All selected adults were our study population. The sampling unit were households.

2.2.2. Inclusion and Exclusion Criteria. All adults greater than 18 years and who lived more than 6 months in the town were included. Severely sick adults were excluded from the study.

\subsubsection{Sample Size Determination and Sampling Strategy.} The total sample size 786 was calculated using single population formula and assuming the proportion of modern health services utilization of $41.8 \%$ [8], 95\% confidence level, and $5 \%$ margin of error and finally adding $5 \%$ nonresponse rate. Multistage systematic random sampling was used. The first 4 kebeles were selected out of 11 kebeles. Then every $\mathrm{k}^{\text {th }}$ household based on their specific house numbers was selected. The head of the family or elder of the family members was interviewed for the questionnaire.

\subsubsection{Data Collection Procedures and Data Quality.} Data were collected using a pretested, interviewer-administered questionnaire adapted from the World Health Organization Manual for the Household Survey to Measure Access and Use of Medicines. The questionnaire was initially prepared in English and translated to Amharic and back to English to maintain consistency of the language. Finally, the Amharic version was used for data collection. Data collection was facilitated by the Open Data Kit (ODK). Trained interviewers who were trained for this purpose were to administer the questionnaire.

\subsection{Variables}

\subsubsection{Dependent Variable. Health Service utilization.}

2.3.2. Independent Variables. Sociodemographic and behavioral factors were age, sex, marital status, occupation, educational status, and perceived health status.

\subsection{Operational Definitions of Terms}

2.4.1. Modern Health Services. Modern health services in this study include public and private licensed health institutions (hospitals, health centers, clinics, and private notfor-profit organizations).

2.4.2. Modern Health Services Utilization. Health services utilization in the study refer to a measure of the health of the population whether the respondent went to modern health institutions in the last 12 months before the study. It is a dichotomous variable based on the survey question ${ }^{\mathrm{a}} \mathrm{Did}$ you go for health care in the last 12 months? $\underline{0}$ Yes $=1$ and No $=0$.

2.5. Data Quality Measures. The quality of data was ensured by pretesting the data collection tools on $5 \%$ of the participants in Bodity town, which has similar sociodemographic characteristics with Woliata Sodo town. Data were collected by 6 BSc in health science students and 3 Masters of Public Health (MPH) graduates supervised the process. Overall Supervision was also carried out at the spot by the principal investigator. The training was given to both data collectors and supervisors on the questionnaire, content interviewing technique, the purpose of the study, and how to maintain the confidentiality of information. To maximize the quality, data were collected by mobile tables. The collected data were checked for completeness and clarity by assigned supervisors and principal investigators. 
2.6. Data Management and Analysis. Data were collected by mobile tablets using Open Data Kit (ODK). ODK is a free mobile application that is designed by Excel. Then data were exported to Excel to Stata Version 15. Descriptive analysis was done for sociodemographic variables using frequency tables and measures of central tendency. Wealth index (WI) was computed by using a principal component factor/PCF/ analysis.

To assess the presence of an association between dependent and independent variables, OR with $95 \%$ confidence intervals (95\% CIs) and the $p$ value were reported on all proportions. The binary logistic regression was used to identify the variables associated with health service utilization. Those of the $p$ values less than 0.25 were the candidate variable for multiple logistic regression. In multiple logistic regression analysis, those variables with a $p$ value $<0.05$ and $95 \%$ CI were considered as significant determinates of health service utilization.

Multicollinearity was checked by using the Variance inflation factors/VIF/and Tolerance test. The HosmerLemeshow tests were checked to assess model goodness-offit.

\section{Result}

3.1. Sociodemographic Characteristics. The total number of participants was 768 , which makes the response rate $97.7 \%$. Of the total respondents, $73 \%$ were females. Seventy-one percent were married. Sixty-four percent of the respondents were Protestant by religion. The median age was 31 years with a range of $18-60$ years, and $23.2 \%$ were in the age category 34-42 years. Most of the study participant's occupations were housewives 193 (25.1\%). Fiftyone percent of the respondents were middle wealth status (Table 1).

Almost all $97.5 \%$ had a health facility nearby with a mean of 30-minute walking distance from health facility ranging from 3 minutes to 60 minutes. Perceived health status was rated to be good for $74.7 \%$. Eleven percent of the respondents have at least one chronic disease. Ninety-eight percent of the respondents have visited health facilities at least once in their lifetime (Table 2).

3.2. Health Service Utilization. Health service utilization was $77.2 \%$ of the respondents with $95 \%$ CI of $74.1 \%, 80.0 \%$ the last year. Thirty-three percent of respondents visited once in the last 12 months. Almost forty percent of the respondents seek health care for cold medical conditions (OPD). Interims of the facility in which they visit first $50.6 \%$ were at public health centers and $25.5 \%$ of them were at teaching and referral hospitals (TRH). Of those who were visiting teaching and referral hospitals, $90.07 \%$ were self-referral. Fifty-one percent of the respondents were satisfied with the service they get (Table 3).

3.3. Health Service Utilization-Associated Factors. Multiple logistic regression analysis showed that respondents with marital status married and widowed have higher odds of utilizing health services compared to single marital status (AOR: 2.96; 95\% CI: 1.7-5.2 and 9.0; 95\% CI: 1.69-48.0), respectively. Respondents with middle and highest wealth status have higher odds of health service utilization than poor wealth status with AOR (1.75 95\% CI 1.03-2.97 and $1.5895 \%$ CI; 1.01, 2.77), respectively. Similarly, respondents who had chronic disease have higher odds of health service utilization with AOR: 7.8, 95\% CI: 2.3-26.5, than their counterparts. Those with perceived poor health status were $96 \%$ more likely to utilize health services than their counterparts (Table 4).

\section{Discussion}

Health service utilization was $77.2 \%$ (95\% CI of $74.1 \%$, $80.0 \%)$ in Wolaita Sodo town. This finding was higher than in Northeast Ethiopia, which is $41.8 \%$ [8]. It is also higher than the study done in Jima, which was 45.6\% [9]. This study might only be for urban residents because urban residents have access to health facilities. It is comparable to a study done in Kenya [10]. Half of them were first to visit primarily at the public health center and $25.5 \%$ of them were at teaching and referral hospitals. Of those who visited university teaching and referral hospitals, $90.07 \%$ were selfreferral.

Factors that affect health service utilization were marital status, wealth status, presence of chronic disease, and perceived health status.

Marital status being married and divorced were more likely to utilize health service. This finding is similar to a study done in Jimma [9]. Wealth status was the main factor in the utilization of modern health services. Middle and high wealth status were more utilized to health services compared to the poor. This finding was similar to the study done by Dessie [8] and Jimma [9] in Ethiopia. Poor people have lower coverage even for basic services such as immunization, sanitation, and antenatal care [1]. This is also in line with the study done in Ghana [11]. This might be due to user fees related to the health service. Removing user fees increases the utilization of curative healthcare services, usually in the form of one sharp stepup following fee removal. Those high and middle wealth status people are capable of paying more than the poor [12].

Those with chronic diseases were 7.8 more likely to use modern health services. This is in line with previous studies, which reported that having chronic conditions was a strong predictor of health care utilization $[8,9]$. This is also in line with studies done in Ghana, which reported that having multiple chronic conditions is a predictor of health service utilization [11].

Perceived health status was also found to be associated with the utilization of health services. Respondents who perceived that their health status was poor were more likely to visit the health institution. This is consistent with the study done in Dessie [8]. This might be because those who perceived that their health was in poor condition seeks treatment and would visit the health institution.

This study had some limitations. 
TABLE 1: Sociodemographic characteristics of Wolaita Sodo residents attending health care utilization survey at Wolaita zone, July 2019 $(N=768)$.

\begin{tabular}{|c|c|c|c|}
\hline \multicolumn{2}{|c|}{ Variable } & \multirow{2}{*}{$\begin{array}{c}\text { Frequency (768) } \\
563\end{array}$} & \multirow{2}{*}{$\begin{array}{c}\text { Percentage } \\
73.3\end{array}$} \\
\hline Sey & Female & & \\
\hline Sex & Male & 205 & 26.7 \\
\hline \multirow{5}{*}{ Age category } & $18-23$ & 168 & 21.3 \\
\hline & $23-28$ & 146 & 19.1 \\
\hline & $28-34$ & 157 & 20.4 \\
\hline & $34-42$ & 178 & 23.2 \\
\hline & $\geq 42$ & 158 & 20.57 \\
\hline \multirow{7}{*}{ Religion } & Protestant & 494 & 64.3 \\
\hline & Orthodox & 214 & 27.9 \\
\hline & Catholic & 10 & 1.3 \\
\hline & Muslim & 38 & 5.0 \\
\hline & Joba witness & 5 & 0.6 \\
\hline & Seventh-day adventist & 5 & 0.6 \\
\hline & Others & 2 & 0.3 \\
\hline \multirow{4}{*}{ Marital status } & Married & 550 & 71.6 \\
\hline & Single & 160 & 20.8 \\
\hline & Widowed & 35 & 4.6 \\
\hline & Divorce & 23 & 3.0 \\
\hline \multirow{5}{*}{ Educational status } & Unable to read and write & 51 & 6.6 \\
\hline & Can read and write & 46 & 6.0 \\
\hline & Primary education [1-8] & 167 & 21.6 \\
\hline & Secondary education [9-12] & 264 & 34.2 \\
\hline & College/university & 245 & 31.7 \\
\hline \multirow{5}{*}{ Spouse's educational } & Unable to read and write & 51 & 6.6 \\
\hline & Can read and write & 46 & 6.0 \\
\hline & Primary education [1-8] & 167 & 21.7 \\
\hline & Secondary education [9-12] & 261 & 21.7 \\
\hline & College/university & 243 & 31.6 \\
\hline \multirow{7}{*}{ Main occupation } & Housewife & 193 & 25.1 \\
\hline & Student & 99 & 12.9 \\
\hline & Employee (gov, private, NGO) & 161 & 21.0 \\
\hline & Merchant & 175 & 22.8 \\
\hline & Daily laborer & 45 & 5.9 \\
\hline & No job & 72 & 9.4 \\
\hline & Others* & 23 & 3.1 \\
\hline \multirow{3}{*}{ Wealth status } & Poor & 109 & 14.19 \\
\hline & Middle & 392 & 51.04 \\
\hline & Highest & 267 & 34.77 \\
\hline
\end{tabular}

* Pension, carpenter, driver, evangelical, and assistant driver.

TABLE 2: Health facility access and perceived health status of Wolaita Sodo residents attending health care utilization survey at Wolaita zone, July $2019(N=768)$.

\begin{tabular}{|c|c|c|c|}
\hline Variable & & Frequency $(768)$ & Percentage \\
\hline \multirow{2}{*}{ Public health center near to your locality } & Yes & 749 & 97.5 \\
\hline & No & 19 & 2.5 \\
\hline \multirow{2}{*}{ The distance of health service in walking minutes } & Less than 30 minutes & 340 & 44.3 \\
\hline & Greater than and equal to 30 minutes & 428 & 55.7 \\
\hline \multirow{2}{*}{ Health status } & Poor & 194 & 25.3 \\
\hline & Good & 574 & 74.7 \\
\hline \multirow{2}{*}{ Chronic disease } & No & 679 & 88.4 \\
\hline & Yes & 89 & 11.6 \\
\hline \multirow{2}{*}{ Ever visited facilities } & Yes & 756 & 98.4 \\
\hline & No & 12 & 1.6 \\
\hline
\end{tabular}


TABLE 3: Health service utilization of Wolaita Sodo residents attending health care utilization survey at Wolaita zone, July 2019 ( $N=768$ ).

\begin{tabular}{|c|c|c|c|}
\hline Variable & & Frequency (768) & Percentage \\
\hline \multirow{2}{*}{ Visited last year } & Yes & 593 & 77.2 \\
\hline & No & 175 & 22.8 \\
\hline \multirow{5}{*}{ Number of times per year visited (593) } & Once & 201 & 33.9 \\
\hline & Twice & 130 & 21.92 \\
\hline & Three times & 75 & 12.65 \\
\hline & Many & 171 & 28.84 \\
\hline & Do not know & 16 & 2.7 \\
\hline \multirow{8}{*}{ Reason for health utilization (593) } & For child health & 98 & 16.12 \\
\hline & For delivery & 20 & 3.29 \\
\hline & For general health checkup & 28 & 4.61 \\
\hline & For cold medical conditions (OPD) & 241 & 39.64 \\
\hline & Maternal and child health $(\mathrm{MCH})$ & 88 & 14.47 \\
\hline & Others & 23 & 3.78 \\
\hline & Chronic diseases follow-up & 70 & 11.51 \\
\hline & For emergency condition & 23 & 3.78 \\
\hline \multirow{4}{*}{ Type of facility utilized (593) } & Nongovernmental organizations (NGO) & 2 & 0.34 \\
\hline & Private clinic/hospital & 139 & 23.48 \\
\hline & Public health center & 300 & 50.68 \\
\hline & Wolaita Sodo University Teaching and Referral Hospital & 151 & 25.51 \\
\hline \multirow{2}{*}{ Source of referral for TRH (151) } & Referred from another facility & 15 & 9.93 \\
\hline & Self-referral & 136 & 90.07 \\
\hline \multirow{4}{*}{ Satisfaction rate for utilized (593) } & Very dissatisfied & 17 & 2.87 \\
\hline & Dissatisfied & 86 & 14.5 \\
\hline & Satisfied & 305 & 51.43 \\
\hline & Very satisfied & 185 & 31.2 \\
\hline
\end{tabular}

TABLE 4: Factors associated with health care utilization of Wolaita Sodo residents, July $2019(N=768)$.

\begin{tabular}{|c|c|c|c|c|c|c|}
\hline \multirow[t]{2}{*}{ Variables $(n=768)$} & \multirow[t]{2}{*}{ Category } & \multicolumn{2}{|c|}{$\begin{array}{c}\text { Health service } \\
\text { utilization }\end{array}$} & \multirow[t]{2}{*}{$p$ value } & \multirow[t]{2}{*}{ COR $(95 \% \mathrm{CI})$} & \multirow[t]{2}{*}{$\operatorname{AOR}(95 \% \mathrm{CI})$} \\
\hline & & Yes $(\%)$ & No (\%) & & & \\
\hline \multirow{2}{*}{ Sex } & Female & $440(78.2)$ & $123(21.8)$ & 0.30 & 1 & \\
\hline & Male & $153(74.6)$ & $52(25.4)$ & & $0.82(0.57,1.2)$ & \\
\hline \multirow{5}{*}{ Age category } & $\leq 23$ & $81(62.8)$ & $48(37.2)$ & & 1 & \\
\hline & $23-28$ & $108(74.0)$ & $38(26.0)$ & 0.047 & $1.7(1.01,2.8)$ & \\
\hline & $28-34$ & $127(80.9)$ & $30(19.1)$ & 0.001 & $2.5(1.5,4.3)$ & \\
\hline & $34-42$ & $142(79.8)$ & $36(20.2)$ & 0.001 & $2.3(1.4,3.9)$ & \\
\hline & $\geq 42$ & $135(85.4)$ & $23(14.6)$ & $<0.001$ & $3.5(2.0,6.1)$ & \\
\hline \multirow{4}{*}{ Marital status } & Single & $95(59.4)$ & $65(40.6)$ & & 1 & 1 \\
\hline & Married & $454(82.6)$ & $96(17.4)$ & $<0.001$ & $3.2(2.2,4.7)$ & $2.69(1.7,5.2)$ \\
\hline & Widowed & $33(94.3)$ & $2(5.7)$ & 0.001 & $11.3(2.6,48.7)$ & $9.0(1.7,48.0)$ \\
\hline & Divorced & $11(47.8)$ & $12(52.2)$ & 0.297 & $0.6(0.26,1.5)$ & $0.5(0.2,1.5)$ \\
\hline \multirow{5}{*}{ Educational status } & Cannot read and write & $43(84.3)$ & $8(15.7)$ & & 1 & \\
\hline & Can read and write & $41(89.1)$ & $5(10.9)$ & 0.489 & $1.5(0.5,5.5)$ & \\
\hline & Primary education [1-8] & $115(68.9)$ & $52(31.1)$ & 0.034 & $0.4(0.18,0.93)$ & \\
\hline & Secondary education [9-12] & $189(72.4)$ & $72(27.6)$ & 0.080 & $0.8(0.22,1.1)$ & \\
\hline & College/TVET/university & $205(84.4)$ & $38(15.6)$ & 0.993 & $1.6(0.4,2.3)$ & \\
\hline \multirow{7}{*}{ Main occupation } & Daily laborer & $35(77.8)$ & $10(22.2)$ & & 1 & \\
\hline & Employee (gov, private, NGO) & $132(82.0)$ & $29(18.0)$ & 0.52 & $1.3(0.6,2.9)$ & \\
\hline & Housewife & $152(78.8)$ & $41(21.2)$ & 0.88 & $1.1(0.5,2.3)$ & \\
\hline & Merchant & $137(78.3)$ & $38(21.7)$ & 0.941 & $1.0(0.5,2.3)$ & \\
\hline & No job & $55(76.4)$ & $17(23.6)$ & 0.862 & $0.9(0.4,2.2)$ & \\
\hline & Student & $65(65.7)$ & $34(34.3)$ & 0.146 & $0.5(0.2,1.2)$ & \\
\hline & Others & $17(73.9)$ & $6(26.1)$ & 0.722 & $0.8(0.3,2.5)$ & \\
\hline
\end{tabular}


TABLE 4: Continued.

\begin{tabular}{|c|c|c|c|c|c|c|}
\hline \multirow[t]{2}{*}{ Variables $(n=768)$} & \multirow[t]{2}{*}{ Category } & \multicolumn{2}{|c|}{$\begin{array}{c}\text { Health service } \\
\text { utilization }\end{array}$} & \multirow[t]{2}{*}{$p$ value } & \multirow[t]{2}{*}{ COR $(95 \% \mathrm{CI})$} & \multirow[t]{2}{*}{$\operatorname{AOR}(95 \% \mathrm{CI})$} \\
\hline & & Yes $(\%)$ & No $(\%)$ & & & \\
\hline \multirow{3}{*}{ Wealth status } & Poor & $75(12.7)$ & $34(19.4)$ & & 1 & 1 \\
\hline & Middle & $304(51.2)$ & $88(50.3)$ & 0.061 & $1.5(1.0,2.5)$ & $1.75(1.03,2.97)$ \\
\hline & Highest & $214(36.1)$ & $53(30.3)$ & 0.019 & $1.8(1.1,3.0)$ & $1.58(1.01,2.77)$ \\
\hline \multirow{2}{*}{ Chronic disease } & No & $507(74.7)$ & $172(25.3)$ & $<0.001$ & 1 & 1 \\
\hline & Yes & $86(96.6)$ & $3(3.4)$ & & $9.7(3.0,31.1)$ & $7.8(2.3,26.5)$ \\
\hline \multirow{2}{*}{ Distance by walking minutes } & Less than 30 minutes & $259(76.2)$ & $81(23.8)$ & 0.541 & 1 & \\
\hline & Greater than and equal to 30 minutes & $334(78.0)$ & $94(22.0)$ & & $1.1(0.8,1.6)$ & \\
\hline \multirow{2}{*}{ Health status } & Poor & $168(28.3)$ & $26(14.8)$ & $<0.001$ & $2.26(1.43,3.56)$ & $1.96(1.19,3.23)$ \\
\hline & Good & $425(71.7)$ & $149(85.2)$ & & 1 & 1 \\
\hline
\end{tabular}

$\mathrm{AOR}=$ adjusted odds ratio, $\mathrm{COR}=$ crude odds ratio, ${ }^{*} \leq 0.05,{ }^{* *} \leq 0.01$.

\section{Conclusion and Recommendation}

Modern health services utilization was found to be unsatisfactory. Being married on marital status, wealth status being middle and high, having chronic health conditions, and having poor perceived health status were found to have a statistically significant association with health service utilization. This indicates that improving the wealth status of the population will possibly result in better utilization of health care.

\section{Abbreviations}

AOR: Adjusted odds ratio

CI: $\quad$ Confidence interval

CMNN: Communicable, maternal, neonatal, and nutritional

COR: Crude odds ratio

LMICs: Low- and middle-income countries

ODK: Open data kit

OPD: Outpatient department

TRH: Teaching and referral hospital

SDG: $\quad$ Sustainable development goals

UHC: Universal health coverage

WI: Wealth index.

\section{Data Availability}

The datasets analyzed during the current study are available from the corresponding author upon reasonable request.

\section{Ethical Approval}

Ethical clearance was obtained from Wolaita Sodo University Institutional Review Board. A letter of permission was secured from the Wolaita Zone administration health office.

\section{Consent}

All study participants were informed about the purpose of the study before the interview. Informed consent was secured from the study participants before taking part in the study. The privacy and confidentiality of the study participants were maintained. Respondents had full right either to take part in the study or not. Any risk associated with the research was minimized if any or avoided at all.

\section{Conflicts of Interest}

The authors declare that they have no conflicts of interest.

\section{Authors' Contributions}

All authors equally contributed to the study.

\section{Acknowledgments}

The authors would like to acknowledge Wolaita Sodo University for providing materials used for the work. Our deepest gratitude goes to data collectors, kebeles leaders, and Wolaita Sodo health center manager for his cooperation, starting from the beginning until the end of data collection time. Last but not the least, our heartfelt thanks go to the respondents. Wolaita Sodo University funded the research.

\section{References}

[1] World Health Organization, Primary Health Care on the Road to Universal Health Coverage: 2019 Global Monitoring Report, WHO, Geneva, Switzerland, 2019.

[2] I. Bonfrer, E. Van de Poel, M. Grimm, and E. Van Doorslaer, "Does health care utilization match needs in africa? Challenging conventional needs measurement," Health Policy and Planning, vol. 29, no. 7, pp. 921-937, 2012.

[3] D. B. Evans, J. Hsu, and T. Boerma, "Universal health coverage and universal access," Universal Health Coverage and Universal Access, vol. 91, no. 8, p. 546, 2013.

[4] V. Obare, C. E. Brolan, and P. S. Hill, "Indicators for Universal Health Coverage: can Kenya comply with the proposed post2015 monitoring recommendations?" International Journal for Equity in Health, vol. 13, no. 1, p. 123, 2014.

[5] N. P. Commission, Growth and Transformation Plan II (GTP II) (2015/16-2019/20), National Planning Commission, Addis Ababa, Ethiopia, 2016.

[6] Federal Ministry of Health, Health Sector Transformation Plan. HSTP 2015/16-2019/20, Federal Ministry of Health, Addis Ababa, Ethiopia, 2015. 
[7] A. Misganaw, T. N. Haregu, K. Deribe, G. A. Tessema, A. Deribew, and Y. A. Melaku, "National mortality burden due to communicable, non-communicable, and other diseases in Ethiopia, 1990-2015: findings from the Global Burden of Disease Study 2015," Population Health Metrics, vol. 15, no. 1, p. 29, 2017.

[8] G. W. Bazie and M. T. Adimassie, "Modern health services utilization and associated factors in North-East Ethiopia," PLoS One, vol. 12, no. 9, 2017.

[9] F. Girma, C. Jira, and B. Girma, "Health services utilization and associated factors in Jimma zone, South west Ethiopia," Ethiopian Journal of Health Sciences, vol. 21, no. Suppl 1, p. 85, 2011.

[10] A. K. Ngugi, F. Agoi, M. R. Mahoney, A. Lakhani, D. Mang'ong'o, and E. Nderitu, "Utilization of health services in a resource-limited rural area in Kenya: prevalence and associated household-level factors," PLoS One, vol. 12, no. 2, Article ID e0172728, 2017.

[11] M. A. Awoke, J. Negin, J. Moller et al., "Predictors of public and private healthcare utilization and associated health system responsiveness among older adults in Ghana," Global Health Action, vol. 10, no. 1, Article ID 1301723, 2017.

[12] M. Lagarde and N. Palmer, "The impact of user fees on health service utilization in low- and middle-income countries: how strong is the evidence?" Bulletin of the World Health Organization, vol. 86, no. 11, pp. 839-848, 2008. 